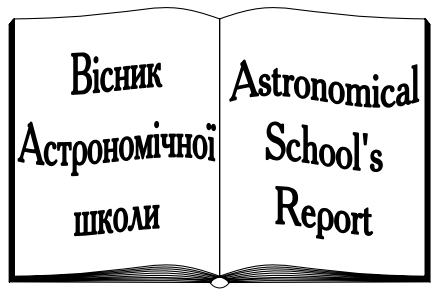

ISSN $1607-2855$

Том 5 • № 1-2 2004 C. $107-110$

UDC 523.59

\title{
Peculiarity of solar radiation scattering by dust in the head of comet $21 \mathrm{P} /$ Giacobini-Zinner in 1985
}

\author{
K.I. Churyumov ${ }^{1}$, F.I. Kravtsov ${ }^{1}$, L.S. Chubko ${ }^{1}$, O.K. Melnik ${ }^{2}$ \\ ${ }^{1}$ Kyiv National Shevchenko University \\ ${ }^{2}$ The high school № 295 of Kyiv
}

On the basis of the polarimetric observations of comet 21P/Giacobini-Zinner the average radius of the dust particles $\rho_{0} \approx 8.5 \cdot 10^{-6} \mathrm{~cm}$, mass and average concentration of dust in the head of comet $21 P$ were estimated.

ОСОБЕННОСТИ РАССЕЯНИЯ СОЛНЕЧНОГО ИЗЛУЧЕНИЯ ПЫЛЬЮ ГОЛОВЫ КОМЕТЫ 21Р/ДЖАКОБИНИ-ЦИННЕРА В 1985 Г., Чурюмов К.И., Кравиов Ф.И., Чубко Л.С., Мелъник Е.К. На основе поляриметрических наблюдений кометы 21P/Джакобини-Циннера получены оценки среднего радиуса пылевых частии, $\rho_{0} \approx 8.5 \cdot 10^{-6}$ см, массы и средней концентрации головы кометы $21 P$.

ОСОБЛИВОСТІ РОЗСІЮВАННЯ СОНЯЧНОГО ВИПРОМІНЮВАННЯ ПИЛОМ ГОЛОВИ КОМЕТИ 21Р/ДЖАКОБІНІ-ЦИННЕРА В 1985 Р., Чурюмов К.І., Кравщов Ф.І., Чубко Л.С., Мелъник О.К. - На основі поляриметричних спостережень комети 21Р/Джакобіні-Циннера отримані оцінки середнъого радіуса пилових частинок $\rho_{0} \approx 8.5 \cdot 10^{-6}$ см, маси і середньої концентрації голови комети $21 P$.

Periodic comet 19P/Giacobini-Zinner was a target for space mission of the ICE probe in 1985 . It allows to compare results of the ground-based and the ICE probe observations.

Comet Giacobini-Zinner was observed with the help of the electropolarimeter installed at the 1-m Richey-Cretiene reflector of Astrophysical Institute of the Academy of Sciences of Republic Kazakhstan on September-October, 1985. Observations were carried out through B, V, R-filters and also through interference narrow band cometary filters centered for wave lengths $4260 \AA\left(\mathrm{CO}^{+}, \Delta \lambda=33 \AA\right) ; 4885 \AA$ (Cont, $\Delta \lambda=37 \AA) ; 5140 \AA\left(\mathrm{C}_{2}, \Delta \lambda=40 \AA\right) ; 6840 \AA$ (Cont, $\left.\Delta \lambda=53 \AA\right) ; 7000 \AA\left(\mathrm{H}_{2} \mathrm{O}^{+}, \Delta \lambda=54 \AA \mathrm{C}\right)[1,2]$. The results of observations are given in the Table 1.

For interpretation of results of polarimetric observations the theory of scattering of light by small spherical particles [3, 7] was used. In the model the normal-logarithmic function of distribution of particles with sizes $f(\rho)$ was taken:

$$
f(\rho) d \rho=\frac{1}{\sigma \sqrt{2 \pi}} \exp \left[-\left(\frac{\ln \left(\rho / \rho_{0}\right)}{\sigma \sqrt{2}}\right)^{2}\right] d \ln \rho
$$

where $\sigma$ is the disperse of a logarithm of radii of particles $\rho ; \rho_{0}-$ their average geometric values. Polarization of comets is studied at wide region of phase angles. In the paper we used an average dependence of a degree of polarization from a phase angle $\theta$ according to [4].

In radiation of a comet always two components are: radiation of emission bands (or lines) and solar radiation scattering by cometary dust. According to A.V.Kurchakov [5]:

$$
P=K P_{n}+(1-K) P_{g}
$$

where $P$ - the observed degree of polarization of radiation in the comet head, $P_{n}-$ a degree of polarization of radiation scattering by dust, $P_{g}$ - a degree of polarization of the emission bands which behaves according to the theory of resonance fluorescence of molecules under the influence of solar radiation 
Table 1. Physical parameters of dust in the head of comet 21P

\begin{tabular}{|c|c|c|c|c|c|c|c|c|c|c|}
\hline $\begin{array}{l}\text { Spectral } \\
\text { region }\end{array}$ & Date & $D^{\prime \prime}$ & $m$ & $\begin{array}{c}E_{0} \\
10^{-10} \mathrm{~W} / \mathrm{cm}^{2}\end{array}$ & $P, \%$ & $K$ & $\kappa$ & $C$ & $M, 10^{6} \mathrm{~g}$ & $\begin{array}{c}n, \\
10^{6} \mathrm{~m}^{-3}\end{array}$ \\
\hline \multirow[t]{7}{*}{0} & 12.09 & 16 & 12.13 & 0.45 & 18.1 & 0.73 & 0.084 & 0.627 & 3.8 & 17 \\
\hline & 13.09 & 16 & 13.03 & 0.41 & 17.7 & 0.69 & 0.083 & 0.627 & 3.4 & 15 \\
\hline & 14.09 & 16 & 13.17 & 0.38 & 18.4 & 0.75 & 0.083 & 0.627 & 3.5 & 15 \\
\hline & 17.09 & 16 & 13.33 & 0.31 & 17.0 & 0.63 & 0.081 & 0.627 & 2.6 & 11 \\
\hline & 19.09 & 16 & 13.22 & 0.35 & 20.6 & 0.90 & 0.080 & 0.627 & 4.4 & 17 \\
\hline & 20.09 & 16 & 13.10 & 0.39 & 16.9 & 0.62 & 0.080 & 0.627 & 3.5 & 13 \\
\hline & 13.10 & 16 & 13.56 & 0.25 & 13.6 & 0.44 & 0.078 & 0.627 & 3.0 & 6.1 \\
\hline \multirow{6}{*}{ V } & 12.09 & 16 & 12.76 & 0.84 & 20.5 & 0.46 & 0.093 & 0.201 & 4.1 & 18 \\
\hline & 13.09 & 16 & 12.36 & 0.77 & 20.1 & 0.45 & 0.093 & 0.201 & 3.8 & 16 \\
\hline & 14.09 & 16 & 12.47 & 0.69 & 20.1 & 0.45 & 0.092 & 0.201 & 3.5 & 15 \\
\hline & 17.09 & 16 & 12.67 & 0.58 & 19.8 & 0.44 & 0.090 & 0.201 & 3.1 & 12 \\
\hline & 19.09 & 16 & 12.55 & 0.65 & 18.5 & 0.39 & 0.088 & 0.201 & 3.3 & 12 \\
\hline & 13.10 & 16 & 12.80 & 0.51 & 14.8 & 0.33 & 0.083 & 0.201 & 4.4 & 8.8 \\
\hline \multirow{7}{*}{$\mathrm{C}$} & 12.09 & 16 & 11.76 & 1.34 & 21.0 & 0.40 & 0.100 & 0.163 & 2.7 & 12 \\
\hline & 13.09 & 16 & 11.81 & 1.28 & 20.7 & 0.39 & 0.099 & 0.163 & 2.6 & 11 \\
\hline & 14.09 & 16 & 11.84 & 1.24 & 20.7 & 0.39 & 0.098 & 0.163 & 2.6 & 11 \\
\hline & 17.09 & 16 & 11.95 & 1.12 & 20.6 & 0.39 & 0.096 & 0.163 & 2.6 & 10 \\
\hline & 19.09 & 16 & 11.94 & 1.13 & 19.1 & 0.34 & 0.094 & 0.163 & 2.4 & 9.0 \\
\hline & 22.09 & 16 & 12.14 & 0.94 & 14.6 & 0.20 & 0.093 & 0.163 & 1.3 & 4.4 \\
\hline & 13.10 & 16 & 12.42 & 0.73 & 13.5 & 0.24 & 0.087 & 0.163 & 2.1 & 4.3 \\
\hline 4260 & 15.09 & 16 & 11.91 & 1.16 & 18.8 & 0.84 & 0.082 & 0.693 & & \\
\hline \multirow{4}{*}{4845} & 15.09 & 16 & 12.61 & 0.61 & 17.3 & 0.51 & 0.085 & 0.493 & & \\
\hline & 16.09 & 16 & 12.64 & 0.59 & 18.2 & 0.57 & 0.084 & 0.493 & & \\
\hline & 14.10 & 48 & 12.21 & 0.87 & 15.4 & 0.48 & 0.079 & 0.493 & & \\
\hline & 15.10 & 48 & 12.24 & 0.85 & 21.4 & 0.83 & 0.079 & 0.493 & & \\
\hline \multirow{3}{*}{5140} & 15.09 & 16 & 12.32 & 0.80 & 19.3 & 0.56 & 0.087 & 0.412 & & \\
\hline & 16.09 & 16 & 12.38 & 0.75 & 19.6 & 0.58 & 0.086 & 0.412 & & \\
\hline & 14.10 & 48 & 11.81 & 1.27 & 11.4 & 0.23 & 0.080 & 0.412 & & \\
\hline 6840 & 16.09 & 16 & 11.74 & 1.37 & 16.9 & 0.27 & 0.096 & 0.174 & & \\
\hline 7000 & 16.09 & 16 & 11.58 & 1.57 & 15.1 & 0.20 & 0.097 & 0.163 & & \\
\hline
\end{tabular}

as $[6]$ :

$$
P_{\theta}=P_{90} \frac{\sin ^{2} \theta}{1+\cos ^{2} \theta}
$$

where $P_{90}$ - polarization of radiation at $\theta=90^{\circ}$ (in accordance with $[6] P_{90}=10 \%$ ). This dependence was confirmed by observations for the all angles $\theta>16^{\circ}[5] ; K$ - a part of radiation scattering by dust in the total radiation of a comet for observable spectral region.

Yanovitsky E.G. and Dumansky Z.O. [7] calculated Tables of degree of polarization $P_{n}$, scattering indicatrix and coefficient of scattering $C$ as functions of a phase angle $\theta$ and average dimensions of a system of spherical dielectric particles which have a normal-logarithmic function of dimension distribution (1) for different dispersion $\sigma^{2}=0.01-0.5$ and for two refraction index $m$ of dust matter: $m_{1}=1.33$ and $m_{2}=1.5$. Right away we note that theoretical $P(\theta)$ for dust particles with $m_{2}=1.5$ does not quite correspond to observable $P(\theta)[4]$.

Using theoretical developments [7] the formula for calculation of mass of dusty atmospheric component was deduced [8]:

$$
M(g)=1.178 \cdot 10^{28} I_{n} \Delta^{2} r^{2} \frac{\rho_{0}^{3} \delta}{F \lambda^{2} \kappa C}
$$


Table 2. Mass, concentration and color of dust in the head of comet $21 \mathrm{P}$

\begin{tabular}{|c|c|c|c|c|c|}
\hline Date & $\bar{M}, 10^{6} \mathrm{~g}$ & $d, 10^{3} \mathrm{~km}$ & $\bar{n}, 10^{6} \mathrm{~m}^{-3}$ & $B-V$ & $V-R$ \\
\hline 12.09 & 3.5 & 5.5 & 16 & 0.18 & 0.33 \\
13.09 & 3.2 & 5.5 & 14 & 0.20 & 0.39 \\
14.09 & 3.2 & 5.6 & 14 & 0.11 & 0.47 \\
17.09 & 2.8 & 5.7 & 11 & 0.50 & 0.58 \\
19.09 & 3.4 & 5.8 & 13 & -0.23 & 0.45 \\
20.09 & 3.5 & 5.9 & 13 & & \\
22.09 & 1.3 & 6.0 & 4.4 & & \\
13.10 & 3.2 & 7.2 & 6.4 & 0.45 & 0.01 \\
\hline
\end{tabular}

Here $I_{n}$ - extra-atmospheric illumination of the unit area $\left(\mathrm{erg} / \mathrm{cm}^{2} \cdot \mathrm{s}\right)$ from scattering radiation of the dust component of the cometary atmosphere in the observable region of the spectrum with the center for the wave length $\lambda(\mathrm{cm}) ; \Delta, r$ - geo and heliocentric distances (A.U.) of a comet; $\delta$ - density of dust matter:

$$
F=\int_{\lambda_{1}}^{\lambda_{2}} f(\lambda) d \lambda
$$

Here $f(\lambda)$ - the flux of the solar radiation in the unit interval of wavelength, passing through unit of surface at the boundary of the Earth atmosphere [9], $\lambda_{1}, \lambda_{2}$ - the boundaries of the observable spectral region.

Calculating dimensions of dust particles we proposed that in the really cometary atmospheres dispersion of dimensions of dust particles may be only maximal one. Therefore in the Tables [7] we took such values of $P, \kappa, C$, which were corresponded $\sigma^{2}=0.5$. Then knowing $\theta$ and observable values of degree of polarization in these Tables we found such values of $\rho$ for which following condition $P \leqslant P_{n} \leqslant P_{g}$ was in progress. So we found $\rho_{0}$ for all spectral regions in which observations were realized. Then these $\rho_{0}$ were averaged for the all observations.

Be founded that for comet $21 \mathrm{P} /$ Giacobini-Zinner $\overline{\rho_{0}}=8.5 \cdot 10^{-6} \mathrm{~cm}$. Using this value $\overline{\rho_{0}}$ and taking into account formulae (2)-(3) the values of were determined (Table 1 ).

Taking $\delta=1 \mathrm{~g} / \mathrm{cm}^{3}$ and using the values of $K, \kappa, C$ from the Table 1 we determined mass of dust in the observable region of the head of comet 21P/Giacobini-Zinner (the Table 2), and also concentration of dust particles $n$ in the head of the comet.

The average concentration of dust particles $\bar{n}$ in the fence of the comet head with the center in its nucleus may be determined by the following formula:

$$
\bar{n}=\frac{\iiint n(\rho, \theta, \varphi) \rho^{2} \sin \theta d \theta d \varphi d \rho}{\iiint \rho^{2} \sin \theta d \theta d \varphi d \rho}=\frac{n_{0} R^{\alpha}}{\alpha+3},
$$

where $n(\rho)=n_{0} R^{\alpha}, R$ - the radius of the fence of the comet head.

Using the data of Table 1, the values of $E_{0}$ and $K$ we determined the values of $B-V$ and $V-R$ for comet $21 \mathrm{P} /$ Giacobini-Zinner: $\overline{B-V}=+0.17 ; \overline{V-R}=+0.36$.

For the Sun $-B-V=+0.65 ; V-R=+0.52$ [9]. It is mean that comet 21P is bluer than the Sun. It may be explained by presence in the head of comet $21 \mathrm{P}$ very small dust particles.

Conclusion. Electropolarimetric observations of comet 21P/Giacobini-Zinner, obtained by K.I.Churyumov et al. during Sept.-Oct. 1985 in Astrophysical Institute of the Academy of Sciences of the Kazakhstan Republic, were processed. The average radius of the dust particles $\rho_{0} \approx 8.5 \cdot 10^{-6} \mathrm{~cm}$, mass and average concentration of dust in the head of comet $21 \mathrm{P}$ were estimated. Also colors $\overline{B-V}$ and $\overline{V-R}$ of the comet dust were determined, which showed that the comet dust was bluer than the Sun.

1. Kurchakov A.V., Nosov I.V., Rspaev F.K., Churyumov K.I. Observations of polarization of comet GiacobiniZinner (1984 e) // Kiev Comet. Circular. - № 350. - P. 4.

2. Churyumov K.I., Rspaev F.K., Gorodetsky D.I. Electrophotometry of comet Giacobini-Zinner (1984 e) // Kiev Comet. Circular. - 1986. - № 356. - P. 3. 
3. Van de Hulst G. Scattering of light by small particles. - Moscow, 1961. - 536 p.

4. Dobrovolsky O.V., Kiselev N.N., Chernova G.P. Polarymetry of comets // Photometric and polarimetric investigations of celestial bodies. - Kyiv: Naukova Dumka, 1985. - P. 3-8.

5. Kurchakov A.V. Photometric study of comet Arend-Roland // Izv. Astrophys. Inst. AN Kaz.SSR. - 1960. 3. - P. 21-28.

6. Dobrovolsky O.V. Comets. - Moscow: Nauka, 1966. - 288 c.

7. Yanovitsky E.G., Dumansky Z.O. Tables of light scattering by polydisperse system of spherical particles. Kyiv: Naukova Dumka, 1972. - 124 p.

8. Kravtsov F.I. Investigation of physical conditions in the neutral cometary atmospheres // PhD. Thesis. - Kyiv, 1990.

9. Allen K.U. Astrophysical quantities. - Moscow: Nauka, 1977. - 448 p.

Received 9.09.2004 